\title{
Vínculos entre Crianças em Situação de Acolhimento Institucional e Visitantes da Instituição
}

Bonds Between Sheltered Children and Visitors of Host Institutions

Vínculos Entre Niños en Situación de Acogida Institucional y Visitantes de la Institución

Karollyne Kerol de Sousa

\& João Luiz Leitão Paravidini

Universidade Federal de Uberlândia
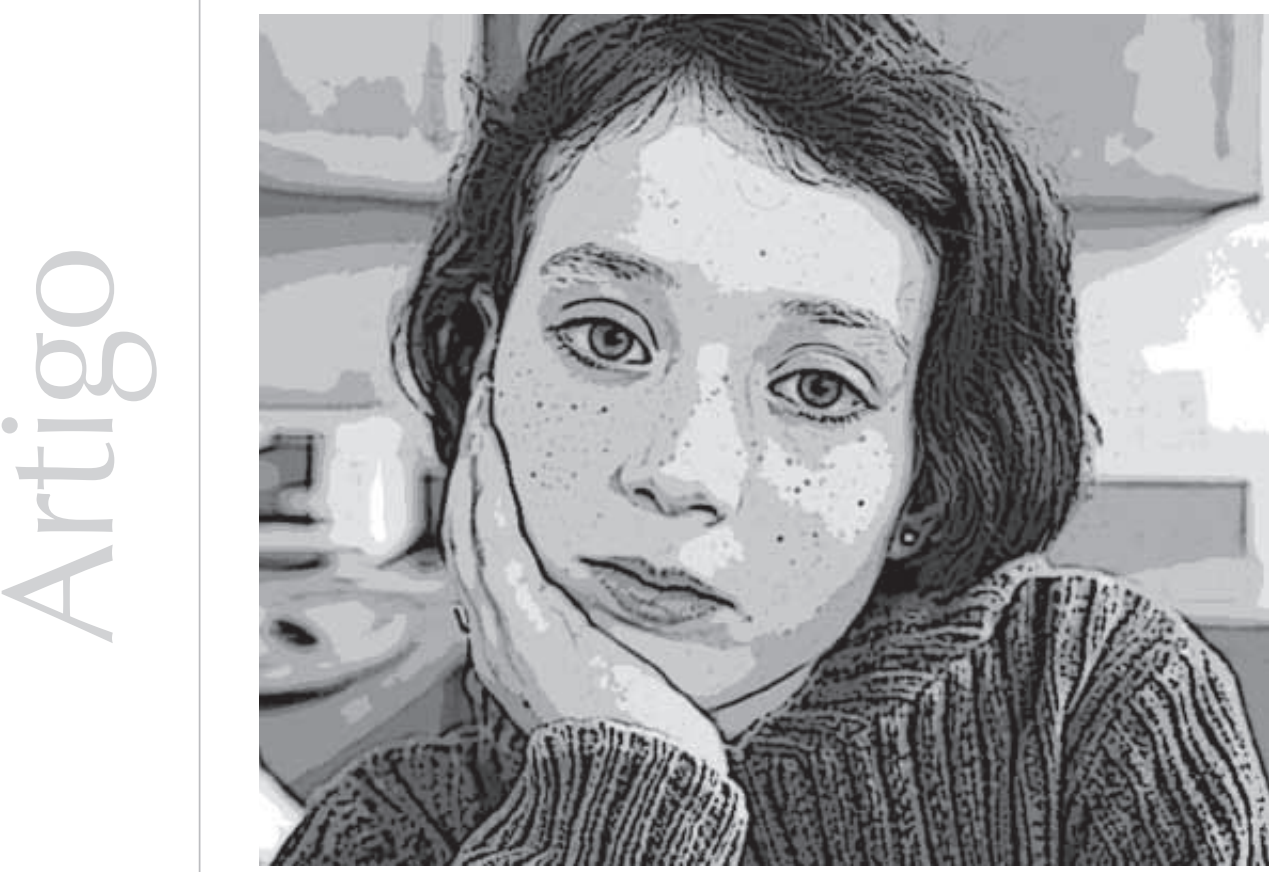
Resumo: Este artigo teve como objetivo principal discutir a forma vincular constituída e constituinte de um processo vigente em muitas instituições de acolhimento a crianças no Brasil, o apadrinhamento afetivo, que pode ser descrito como uma forma de proporcionar às crianças vínculos alternativos dotados de significado através da sua relação com as pessoas que as visitam nas instituições de acolhimento. Entretanto, percebe-se que o apadrinhamento tem sido usado como um dispositivo para preencher lacunas existenciais, tanto pela via da criança como do padrinho. Depois de um breve percurso pela situação da infância institucionalizada, foram analisadas quatro entrevistas com madrinhas e o caso clínico de uma criança apadrinhada. O método psicanalítico foi utilizado como instrumento de pesquisa, e, a partir de analisadores elencados, importantes reflexões foram construídas em relação ao processo de apadrinhamento: exaltação da solidariedade, correlacionada a sentimentos como a bondade e o amor ao próximo, narcisismo exacerbado como tentativa de recuperar a onipotência perdida nos primórdios da existência, a sedução que perpassa a relação padrinhocriança institucionalizada, a ambivalência de sentimentos despertados nessa relação e as semelhanças do processo de apadrinhamento com o processo de adoção, no que diz respeito à busca do filho ideal, que se estende à procura do padrinho ideal e do afilhado ideal.

Palavras-chave: Comportamento de apego. Crianças institucionalizadas. Co-dependência (Psicologia). Psicanálise.

Abstract: This article aims to discuss a form of bond in the practice of acting as a godfather/godmother in
some host institutions in Brazil. This can be described as a way to give children alternative significant bonds
through the relationship between children and the people who visit them in the host institutions. Nevertheless,
it can be noticed that this practice has been used as a way to fulfill existential gaps. After a short verification
of the sheltered children situation, we analyzed four interviews with godmothers of sheltered children and
a clinical case of a godchild. The method used for the research was the psychoanalytic method. From the
analyzers listed in the interviews, important reflections were constructed about the way of the relationship
fostered by being a godfather: the exaltation of solidarity, correlated with feelings like goodness and love for
the other one, an exacerbated narcissism as an attempt to recover the omnipotence felt in the beginning of
life, the seduction that permeates the relationship between the godfather and the sheltered children, the
ambivalence of feelings aroused in this relationship and the similarities of the act of being a godfather with
the adoption process, according to the search for the ideal son, that is extended to the search for the ideal
godfather/godmother and the ideal godchild. Keywords: Attachment behavior. Children institutional care. Codependency (Psychology). Psychoanalysis.

Resumen: Este artículo ha tenido como objetivo principal discutir la forma vincular constituida y constituyente de un proceso vigente en muchas instituciones de acogida de niños en Brasil, el apadrinamiento afectivo, que puede ser descripto como una forma de brindar a los niños vínculos alternativos dotados de significado a través de su relación con las personas que las visitan en las instituciones de acogida. Sin embargo, es notable que el apadrinamiento ha sido utilizado como un dispositivo para rellenar huecos existenciales, tanto por el lado del niño como por el del padrino. Luego de un pronto recorrido por la situación de la niñez institucionalizada, se han analizado cuatro entrevistas con madrinas y el caso clínico de un niño apadrinado. El método psicoanalítico ha sido llevado a cabo como instrumento de investigación, y, partiendo de análisis enumerados, importantes reflexiones han sido construidas en relación al proceso de apadrinamiento: exaltación de la solidaridad, correlacionada a sentimientos como la bondad y el amor al prójimo, narcisismo exagerado como intento de recuperar la omnipotencia perdida en los primordios de la existencia, la seducción que rebasa la relación padrino-niño institucionalizada, la ambivalencia de sentimientos despertados en esa relación y las similitudes del proceso de apadrinamiento con el proceso de adopción, en lo que respeta a la búsqueda del hijo ideal, que se extiende a la búsqueda del padrino ideal y del ahijado ideal.

Palabras clave: Conducta de apego. Niños institucionalizados. Codependencia (Psicología). Psicoanálisis.

Este artigo é resultado de uma pesquisa de mestrado e tem como objetivo principal discutir as formas vinculares constituídas e constituintes de um processo vigente em muitas instituições de acolhimento a crianças no Brasil, o apadrinhamento afetivo. Após uma revisão na literatura, verificamos a escassez de estudos científicos específicos sobre o tema. Em contrapartida, encontramos inúmeros sites da internet ${ }^{1}$ que falam sobre o apadrinhamento, com o objetivo quase que exclusivo de convocar pessoas a contribuir afetiva e/ou financeiramente para o desenvolvimento físico e/ou psíquico de crianças em situação social desfavorecida, seja em acolhimento institucional, seja como 
um auxílio a comunidades em situação de pobreza e miséria.

A partir dessas constatações iniciais e das experiências possibilitadas por esta pesquisa, definimos o apadrinhamento afetivo como uma prática que intenta proporcionar às crianças acolhidas vínculos alternativos dotados de significado, que contribuam para que elas tenham vivências familiares e emocionais saudáveis ao seu desenvolvimento psíquico.

Considerando a importância das origens, é importante mencionar que o nascedouro desta pesquisa se deu por meio de atendimentos psicoterápicos a crianças institucionalizadas na Clínica de Psicologia da Universidade Federal de Uberlândia. A realidade daquelas crianças nos fez pensar como era possível nascer ali um sujeito desejante, diante dos percalços do tempo e das rupturas de vínculos vivenciadas por elas.

Apesar da singularidade característica de cada uma das histórias de crianças em situação de acolhimento institucional, um contexto abrangente se apresenta, uma jornada marcada por violências, negligências, abandonos, sejam eles físicos ou psíquicos, contornada por um lugar, a instituição familiar. Esta, por sua vez, carrega consigo condições de vida precárias, também marcadas, muitas vezes, pelos mesmos infortúnios vivenciados pelas gerações de filhos, como uma corrente que se arrasta demarcando e limitando destinos.

As instituições de acolhimento a crianças em situação de risco psicossocial funcionam como uma tentativa de proteger a infância desvalida (Venâncio, 1999). São lugares constituídos por um corpo de funcionários denominados cuidadores, envolvidos na tarefa de acolher e de cuidar das crianças separadas de suas famílias de origem, como as mães sociais, responsáveis pelo cuidado diário das crianças, além de pedagogas, psicólogas, coordenadores e motoristas, entre outros. São comumente instituições sustentadas por entidades não governamentais, como igrejas, por exemplo. As crianças frequentam escolas e possuem atividades de lazer, como passeios fora da instituição.

Além de uma indispensável estrutura física e material, as crianças necessitam construir e manter laços vinculares, relações significativas com pessoas que se enderecem a elas e a quem elas também possam se endereçar (Jerusalinsky, 2005). É fundamental que advenham desses vínculos experiências de afeto, gratificações e frustrações, que, combinadas, possam permitir a simbolização desses laços no imaginário das crianças (Chasseguet-Smirgel, 1992). A partir desse prisma, é possível pensar e discutir sobre o lugar chamado instituição de acolhimento como possibilidade de subjetivação para crianças, e não como destino de infelicidades e desatinos.

Impregnados por leituras sobre a psicopatologia na infância, resultante da perda repentina de vínculos de afeto significativos, percorremos trilhas de pessimismo, pensando que aquelas crianças atendidas durante o estágio na clínica, entre outras tantas em situação de acolhimento institucional, estavam fadadas a adoecer psiquicamente, caso não fossem salvas por um adotante. Mas o caminho que foi se revelando é que, a despeito das inúmeras psicopatologias encontradas nos estudos sobre crianças abrigadas, é possível, sim, alcançar formas subjetivantes, desejantes, almejantes de sonhos, de crescimento e de amadurecimento emocional. A partir de então, nosso olhar passou a ser destinado a novas direções. Percorrendo o espaço do abrigo, pudemos ver crianças que se apropriavam de sentidos de existência, de vida, e não de morte.

Foi durante a visita a uma instituição de acolhimento que os padrinhos de crianças 
institucionalizadas despertaram nossa atenção, pessoas que, de alguma forma, convocam as crianças a comparecer em um campo de significação humana, já que os pequenos são sujeitos capturantes de tudo o que aí se coloca.

Mas o que vem a ser, essencialmente, um padrinho de criança institucionalizada? Comecemos pelo significado da palavra, da qual originou a expressão apadrinhamento. Padrinho/madrinha são termos de cunho religioso que significam pais e mães espirituais, que exercem a função de segundo pai e de segunda mãe, a função de proteger (Bueno, 2007). Na falta do pai e da mãe, são os padrinhos os responsáveis pelo cuidado e pela criação das crianças. A palavra padrinho tem muito a nos revelar sobre as relações constituídas e constituintes do campo institucional, e é sobre esse terreno que iremos nos debruçar. A que vem a função do apadrinhamento? Que forma de se formar laço social é essa?

$\mathrm{Na}$ instituição de acolhimento em que foi realizada esta pesquisa, bem como em outras na cidade de Uberlândia-MG, o apadrinhamento afetivo pressupõe um modo de se estabelecer relações entre crianças institucionalizadas e visitantes da instituição, de tal modo que os padrinhos, como são chamados alguns visitantes, vão até as crianças, o que caracteriza a visitação, e as levam para passear, seja em suas casas, seja em outros lugares conotativos de lazer e prazer. Algumas vezes, são levadas também para atendimentos psicológicos, médicos, odontológicos e fisioterapêuticos. Há um padrinho para cada criança, e, normalmente, não se pode ser padrinho de duas crianças ao mesmo tempo. Apenas uma é levada, a não ser que tenha irmãos e o padrinho queira levá-los também.
Muitos apadrinhamentos veiculados pela internet $^{2}$ diferem desse que acabamos de mencionar. Em alguns deles, o contato físico com as crianças não ocorre, e por isso não tem a denominação de afetivo. Nessas situações, os padrinhos/madrinhas são pessoas que auxiliam financeiramente uma criança em situação de risco psicossocial e que recebem informações sobre o seu desenvolvimento. Em certos casos, as crianças se correspondem com os padrinhos através de cartas em datas comemorativas e aniversários, recebem presentes e seguem prazos para responder às cartas enviadas pelos padrinhos.

Todo esse contexto nos leva a pensar naquilo que move o desejo de apadrinhar e de ser apadrinhado, desejo que toca nossa própria condição humana de desamparo. O que podemos considerar a priori é que o desejo de ser apadrinhado está atrelado ao desejo de ser adotado, ao desejo de ser querido por alguém, desejo de ser o objeto de desejo de outrem. Sinteticamente, quando nos fundamentamos em Freud (1914/1996), falamos sobre o desejo de ser amado.

A partir de uma lógica institucional, importa, pois, avaliar as relações interpessoais que ali se dão como uma possibilidade de estarem sendo tecidas novas configurações familiares, apesar de esse ser um ambiente que possui limitações, também presentes em muitos outros contextos, se nos respaldarmos no que nos diz Neves (2009) sobre família em sua condição não ideal. A despeito de a institucionalização de crianças ser medida de caráter excepcional e provisório, de acordo com o Estatuto da Criança e do Adolescente (ECA (1990)), o que se sabe é que elas são colocadas nas instituições de acolhimento por tempo indeterminado, à espera de uma nova família ou do retorno à própria família renovada. Parecem vivenciar, nesse lugar, relações familiares com uma estrutura diferente das famílias tradicionais. Os padrinhos, visitantes, voluntários, funcionários da instituição e todas as crianças que ali estão podem estar fazendo parte de uma tessitura familiar. 
É fundamental destacar que "a função materna e paterna não se estabelecem por uma correspondência a personagens fixos" (Jerusalinsky, 2005, p.10). Isso significa que outras pessoas podem exercer os papéis resguardados a pais e mães, sustentando suficientemente o desenvolvimento físico e psíquico de crianças afastadas do convívio com pais biológicos, como reforça Winnicott (2000), ao falar sobre o ambiente suficientemente bom. Pensando sob essa perspectiva, é nesse ambiente-mundo que as crianças se constituem psiquicamente. Resta a nós, pesquisadores, investigar a sustentabilidade do exercício das funções materna e paterna por essa possível família extensa, apontada por Jerusalinsky (2005).

Para avaliar essas questões abordadas, fazse necessário situar o leitor no contexto em que as crianças em situação de acolhimento institucional estão inseridas.

\section{Um breve percurso sobre a atual situação da infância institucionalizada}

Falemos um pouco da realidade das crianças acolhidas na cidade de Uberlândia. São aproximadamente 185 crianças que vivem hoje em oito instituições de acolhimento em Uberlândia (Silva, 2010). O interessante é que o número de candidatos à adoção ultrapassa o número de crianças acolhidas. Isso quer dizer que, se não fossem as exigências dos candidatos, todos já teriam família, já que, agora, a destituição do poder familiar foi acelerada em virtude das mudanças nas leis que regem esse processo, que determinam um tempo máximo de dois anos de permanência da criança na instituição.

A preferência da maioria dos candidatos brasileiros direciona-se a crianças de até três anos, de cor branca, saudáveis e que não sejam prematuras (Silva, 2010). Em Uberlândia, essas preferências se confirmam, de acordo com Silva. Esses dados nos interessam, na medida em que deflagram uma questão fundamental à compreensão da prática do apadrinhamento: a busca pelo filho ideal. De acordo com a responsável pelo cadastramento de candidatos à adoção, 95\% das famílias brasileiras escolhem o perfil do futuro filho, ao contrário das famílias estrangeiras (Silva, 2010). Segundo a agente da Vara da Infância e da Juventude de Uberlândia, enquanto as famílias estrangeiras buscam crianças ou adolescentes para aumentar suas famílias, as brasileiras procuram uma criança para fazer de conta que tiveram um filho biológico e mostrarem-no para a sociedade. A comprovação dessa realidade está no fato de que, no ano 2009, 16 de 29 crianças foram adotadas por famílias estrangeiras, mesmo tendo prioridade as famílias do Município, em seguida, as do Estado e, depois, as do País (Silva, 2010). A adoção internacional só é efetivada quando as outras possibilidades são descartadas.

Segundo relatos de profissionais da Vara da Infância e da Juventude de Uberlândia, a prática do apadrinhamento está suspensa por falta de determinações legais. A principal justificativa dessa suspensão é a de que o ato de apadrinhar tem prejudicado o funcionamento dos processos jurídicos e trazido complicações para as crianças, porque muitas pessoas se propõem a apadrinhar, mas depois não mantêm o compromisso. Ainda segundo relatos de profissionais da área, são pessoas que, por diversas razões, se candidatam ou são chamadas pelas crianças a ocupar o lugar de padrinhos, levam as crianças para suas casas, passeiam com elas e, algum tempo depois, se afastam do posto assumido a princípio, deixando-as com sentimentos de tristeza e frustração. Além disso, cria-se uma expectativa na criança de que ela poderá ser adotada pelos padrinhos, o que, geralmente, não ocorre, ou seja, a adoção não se concretiza, causando intenso sofrimento à criança. 
Nesse contexto, para avaliar o processo de apadrinhamento, percorremos caminhos para além da situação atual da adoção no Brasil, intimamente ligada ao apadrinhamento, considerando que se trata de relações vinculares em um campo institucional cuja premissa básica é a de propiciar um ambiente familiar a crianças abandonadas ou afastadas dos pais por razões extremas, sustentados pelas determinações do ECA (1990). Propomos uma reflexão sobre a constituição do sujeito psíquico e sua possibilidade de amadurecimento emocional no contexto de uma instituição, enfatizado por seu limitado aporte afetivo, através dos estudos teóricos de Winnicott (1975/2000) e Jerusalinsky (2005). Nesse sentido, indagamos acerca dessa limitação no intento de repensar um lar ideal, supostamente presente em uma família de moldes tradicionais, ancorada nos pensamentos de Neves (2009). Propomos ainda pensar sobre a possibilidade de construção de sentidos significativos para a subjetivação na infância abrigada, por meio da relação de crianças com adultos que encarnam funções paternas e maternas, oferecendoIhes um olhar simbólico constitutivo, como os padrinhos, fundamentados no que argumenta Jerusalinsky (2005) acerca dessas funções.

Logo nos deparamos com questões mais complexas, referentes às formas de vinculação presentes na contemporaneidade, amparada pelas formulações teóricas de Freud (1912/1 914/1915/1924/1929/1933), Birman (2006) e Chasseguet-Smirgel (1992). A relação das crianças institucionalizadas com os padrinhos vem denunciar a incessante trajetória do sujeito na busca pela felicidade, em que a submissão ao outro traduz uma tentativa de reencontrar a perfeição perdida nos primórdios de nossa existência (ChasseguetSmirgel, 1992). Essa relação pode gerar sofrimento, principalmente para as crianças, se engajadas em vínculos insustentáveis com os padrinhos, não simbolizados, carentes de registro no psiquismo. Nessa direção, percorremos conceitos como o narcisismo (Freud, 1914/1996), a servidão voluntária (Birman, 2006) e o masoquismo (Freud, 1924/1997), dentre outros, que nos servirão de aporte teórico para pensar sobre as formas de subjetivação contemporâneas em um campo institucional como esse.

Fundamentados nesses balizadores teóricos e tendo em vista a atual situação da infância institucionalizada, faz-se necessária uma investigação sobre o processo de apadrinhamento afetivo, que denuncia dinâmicas institucionais importantes e que nos leva a repensar as práticas vigentes na contemporaneidade. É partindo dessa necessidade que nos propomos a percorrer o campo da subjetivação humana por meio de um olhar voltado para as formas vinculares, estabelecidas entre padrinhos e crianças em situação de acolhimento institucional, caminho sustentado pelo método psicanalítico.

\section{Método}

O método psicanalítico é um método de investigação que toma como objeto o inconsciente e, como fundamento essencial, a interpretação. As técnicas utilizadas são a associação livre, que possibilita a emergência de formações do inconsciente, e a atenção flutuante, que, para Freud (1912/1974), significa manter a atenção uniformemente suspensa em tudo que se escuta. Nessa lógica inconsciente, estão inscritas pulsões, marcas identificantes, suas relações com os objetos de satisfação e com o Outro (Birman, 1993).

Inaugurado por Freud, o método psicanalítico trouxe relevantes mudanças nas formas de se fazer pesquisa ao abandonar a noção de que deve haver uma distância entre investigador e objeto investigado. É o que explica Silva (1993), ao destacar que o 
Seguindo o método psicanalítico, o inconsciente pode se revelar na articulação entre linguagem e pulsão, "enquanto real da língua incidindo sobre um corpo" (Guerra, 2001, p.3). método psicanalítico é uma forma de investigação em que sujeito e objeto se criam mutuamente. De acordo com essa autora, qualquer modelo que desconsidere a subjetividade dos envolvidos é incompatível com a natureza do psiquismo humano.

Freud (1912/1974) nos faz uma importante advertência, de que não devemos iniciar uma pesquisa já com uma seleção prévia do que poderemos encontrar baseados em expectativas próprias, pois, assim, estaremos nos arriscando a não descobrir nada além daquilo que já sabíamos, ou até a falsificar aquilo que se possa saber. Ele afirma: "O analista é certamente capaz de fazer muito, mas não pode determinar de antemão exatamente quais os resultados que produzirá" (p.172).

Seguindo o método psicanalítico, o inconsciente pode se revelar na articulação entre linguagem e pulsão, "enquanto real da língua incidindo sobre um corpo" (Guerra, 2001, p.3). Mas, entre o significante e a pulsão, existe uma lacuna, que permite a emersão do desejo e que, ao mesmo tempo, nos impede de acessar todo o conteúdo inconsciente. A linguagem não dá conta de apreender todas as experiências (Guerra, 2001).

Entendemos, a partir de Freud, que os restos deixados como traços, possivelmente acessíveis por meio de uma análise, seriam os elementos que estruturam e organizam um discurso (Guerra, 2001). Isso denota que mais importa aquilo que não pode ser apreendido de imediato, o que não foi dito ou escrito, ou seja, "aquilo que se constrói no silêncio do lado avesso ao significante" (Guerra, 2001, p.93), acessível somente através do poder da escuta analítica.

Ancorado nessas proposições, este trabalho de investigação foi realizado por meio da análise de entrevistas abertas com quatro madrinhas de crianças institucionalizadas e do caso clínico de uma criança apadrinhada. Entende-se por entrevista aberta aquela em que não há um roteiro predeterminado de perguntas a ser seguido. O entrevistado recebe apenas um estímulo que o instigue a falar sobre sua relação com as crianças institucionalizadas.

Os contatos com os padrinhos foram disponibilizados por uma instituição de acolhida onde a prática de apadrinhamento adquire um significado importante. As madrinhas entrevistadas foram aquelas que se dispuseram a falar sobre a relação com as crianças abrigadas.

A eleição do caso clínico e das quatro entrevistas se fez necessária por acreditarmos ser fundamental a articulação entre os aspectos inconscientes das crianças e os das madrinhas. Foi a tentativa de se fazer um estudo de dois pêndulos que trabalhassem com ambas as perspectivas, e que pudessem, nesse sentido, alcançar discussões mais ricas no que diz respeito ao campo de significação humana. A proposta inicial era a de se fazer entrevistas com padrinhos e madrinhas de crianças institucionalizadas, entretanto, com o decorrer da pesquisa, o contato só foi concretizado com as madrinhas.

Por meio de uma escuta analítica, proposta por Freud (1912/1974), e de uma análise interpretativa do conteúdo das entrevistas e do caso clínico, foi possível trazer à tona questões importantes para se pensar sobre o objetivo do trabalho. É importante frisar que esses fragmentos estão tomados pela condição de terem sido dimensionados a partir do que circunda o campo analítico, a transferência. É fundamental salientar que o número de madrinhas entrevistadas não foi um fator relevante para os fins desta pesquisa. As entrevistas foram suspensas quando percebemos que havia um fio condutor que perpassava todas elas, e que forneciam um 
material imprescindível para buscarmos compreender a lógica dessa relação padrinho-afilhado. Em relação ao caso clínico, interessa-nos destacar que, para Safra (1993), a investigação do particular possibilita compor modelos mais abrangentes do psiquismo humano, mesmo com toda a singularidade que o caso apresenta.

\section{Entre o desejo de apadrinhar e o de ser apadrinhado: uma síntese das entrevistas com madrinhas e do caso clínico de uma criança apadrinhada Entrevistas}

Através do conteúdo das entrevistas e do caso clínico, poderemos pensar sobre o que há de substancial na função de apadrinhamento. As entrevistas têm aspectos divergentes e convergentes. São madrinhas com histórias de vida diferentes, mas que se entrelaçam em sentidos semelhantes.

Inicialmente, as madrinhas foram instigadas por um dos pesquisadores a falar sobre as crianças em situação de acolhimento institucional. O que marca o começo do relato de três das madrinhas entrevistadas é a carência das crianças institucionalizadas e os sentimentos despertados por essa condição. Falam de uma forma que sugere preocupação com o que falta às crianças, como roupas, afeto, individualidade, alimentos, enfim, enfatizam as suas inúmeras carências. Discorrem sobre como podem restituir e/ ou oferecer às crianças coisas que elas possivelmente perderam ou nunca tiveram, como laços afetivos e condições materiais, um guarda-roupa individual, roupas, brinquedos, passeios, futuro. Falam também da facilidade em agradar as crianças e do papel solidário que fazem ao ajudá-las. Os sentimentos marcantes nos relatos são a piedade e a compaixão.
A quarta madrinha entrevistada inicia sua fala dizendo direta e imediatamente o que a levou ao abrigo, um acidente de família. Jovem, perdeu o marido em um acidente e pensou que jamais se casaria de novo, por isso optou por apadrinhar para conhecer a criança e depois, possivelmente adotá-la. Passados dois anos e alguns meses, compreendeu que a adoção seria uma forma de superar uma perda, e, a partir de então, decidiu que seria apenas madrinha. Durante esse processo, a criança apadrinhada ficou em sua casa por um mês, em uma convivência intensa, já que a madrinha tirou licença do trabalho para se dedicar exclusivamente a ela. A madrinha conta que a criança se parecia fisicamente com seu falecido marido.

As madrinhas enfatizam a relação de afeto que constroem com as crianças que apadrinham. Falam da alegria com que as crianças as recebem nos dias de visita e da tristeza com que se despedem no momento da sua partida. Por meio da fala sobre os sentimentos despertados na relação, as madrinhas contam sobre a vontade de adotar a criança que apadrinharam. Relatam inúmeros empecilhos para concretizar a adoção, como a postura negativa de seus companheiros e $\mathrm{o}$ pensamento de que não é o momento ideal para uma adoção, tendo em vista a fase da vida em que se encontram. Outros conteúdos importantes, mas ainda encobertos nas falas, culminam na desistência do processo de adoção. Dentre eles, temos as histórias de sofrimento das crianças, as vivências precoces na infância e a preocupação com a sua carga genética, com as heranças familiares. Mesmo assim, reforçam como a relação de afeto com as crianças é significativa e como se confundem na função de mãe ou madrinha.

Ao falar sobre como funciona o apadrinhamento, as madrinhas dizem que não há determinações legais de que se deve visitar a criança todos os fins de semana, posto que as visitam quando podem e as levam para 
passeios também quando é possível para elas. Relatam que alguns padrinhos iniciam o contato com as crianças porque a instituição de acolhimento se mobiliza para encontrar pessoas que as recebam em suas casas no Natal, e esse contato inicial pode perdurar ou não. Alguns passam apenas o Natal e depois perdem o contato com a criança, assim como fazem alguns visitantes que se tornam padrinhos por interesse próprio ou por pedido das crianças, mas não mais retornam à instituição. Em contrapartida, as madrinhas entrevistadas falam sobre a intenção de cuidar da criança apadrinhada pelo resto de suas vidas.

\section{Caso clínico}

A criança apadrinhada é Maria, 13 anos, abrigada aos 10. Vivia com os avós maternos e a mãe biológica, e não conheceu o pai. Por denúncias de vizinhos, Maria foi abrigada. Sofria de negligência familiar e de maus tratos. Sua família vivia em condições impróprias de higiene, armazenanando lixo dentro de casa e consumindo água não tratada. A avó materna sofre de um transtorno mental, e a mãe é garota de programa. Maria tem mais seis irmãos, cada um de um pai diferente, e cada um vive com o respectivo pai. Foi destituída do poder familiar em 2009, está na lista de espera para ser adotada e foi apadrinhada por dois casais de maneira informal, ou seja, sem o registro da Vara da Infância e da Juventude da cidade.

Maria começou a frequentar a escola aos 10 anos, quando foi abrigada. Até então, não sabia ler nem escrever. Apesar disso, está no quarto ano. Segundo a instituição que a acolheu, Maria é uma ótima copiadora e também não poderia ser colocada em uma série em que as crianças fossem bem menores que ela.

Maria vive em uma casa no espaço da instituição de acolhimento com mais dez crianças e a mãe social. Ao todo, são sete casas-lares, como são chamadas as casas em que vivem as crianças, cada uma com uma mãe social.

A assistente social da instituição de acolhimento em que vive Maria procurou atendimento psicológico para a criança, e explicou que seus padrinhos, Rita e Jorge, estavam dispostos a pagar esse atendimento. Primeiro, foi ao atendimento a assistente social da instituição para falar sobre Maria; depois, foi Maria. Após algumas sessões e tentativas de falar com Rita, marcamos uma sessão com a madrinha.

Rita veio sozinha, sem o marido, que, na ocasião, viajava. Ela falou sobre os prejuízos de aprendizagem de Maria, seus problemas com a higiene, com a sexualidade e com o xixi. Rita disse que Maria tem sérios comprometimentos na área escolar, não sabe ler, só sabe escrever copiando de outros lugares, não sabe cuidar de sua higiene, lavar os cabelos e escovar os dentes, tem interesses sexuais precoces, porque, quando vai a sua casa, quer sair para se relacionar com os meninos do condomínio em que vive. Além disso, faz xixi na cama. Rita contou que havia dito a Maria que, quando ela fizesse xixi na cama, não iria buscá-la para passar o fim de semana em sua casa.

Ainda durante essa mesma sessão, Rita informou que havia adotado duas meninas recentemente, um pouco mais novas que Maria. Na época, já conhecia Maria, mas disse que não a adotou por causa da idade e também por temer suas limitações. Explicou que ainda está à procura de mais uma menina para adotar, e que, por seu marido, adotariam Maria, mas que não se sente segura para isso, principalmente por causa da idade da menina.

Depois de algumas semanas de atendimento, no dia de acertar o primeiro pagamento da 
psicoterapia, Jorge, padrinho de Maria, diz querer conversar com a psicoterapeuta. Marcamos uma sessão. Ele veio sozinho, sem a esposa Rita. Demonstrou-se preocupado com Maria. Contou sobre o xixi, foi questionado sobre o significado desse fato e respondeu que achava que era uma afronta, uma rebeldia de Maria. Foi esclarecido a ele que o xixi é um sintoma que, ao contrário de ser punido, necessita ser compreendido. Jorge disse que tomou a atitude de não levar Maria para passear quando faz xixi na cama durante a semana, porque a instituição o instruiu assim, e a instituição informou que essa havia sido uma decisão dos padrinhos, quando a psicóloga da instituição foi solicitada a falar sobre Maria. A psicóloga reafirmou a teoria de Jorge, de que o xixi é uma forma de Maria desafiar a autoridade de toda a equipe de trabalho da instituição e que, quando dizem que ela só vai passear com os padrinhos se não fizer xixi na cama, Maria não faz. Foi conversado com Jorge sobre as possíveis representações do xixi para Maria, como uma possível regressão, o desejo de ser pequena para poder ser adotada.

Jorge comentou que está muito preocupado também com as dificuldades de Maria em relação ao conteúdo escolar. Perguntou se, com a psicoterapia, ela iria vencer essas limitações. Foi explicado a ele que parte dessas dificuldades advém de seu estado emocional, mas a outra parte se deve ao fato de que Maria começou a frequentar a escola aos 10 anos, em uma turma mais avançada em termos de conteúdo. Foi orientado sobre a necessidade da alfabetização de Maria, trabalho para uma psicopedagoga especializada. Ele concordou, e pediu uma indicação. Poucos dias depois, Maria iniciou o acompanhamento psicopedagógico.

Ao longo dos atendimentos, percebemos que, apesar das queixas dos padrinhos, Maria permanecia tentando encobrir alguns aspectos importantes. O xixi, as dificuldades escolares, a cabeça sem lavar, tudo isso estava presente, mas parecia não poder ser dito. $\mathrm{O}$ que Maria tinha de humano necessitava ser escondido, o que poderia ser mostrado eram as suas proezas. Estas, sim, poderiam ser valorizadas. O seu silêncio perante as suas vacâncias demarcava os limites de seu corpo e de sua alma.

É imperioso retornarmos aos primeiros movimentos de Maria nas sessões psicoterápicas. No começo, ela se recusava a ler quaisquer enunciados, como os que fazem parte dos jogos que escolhia para brincar. Tentava se justificar dizendo que não queria ler. Era instigada a tentar, que não haveria problema se errasse ou se não soubesse tudo o que estava escrito. Ela dizia que tinha vergonha. Mas, com o auxílio psicoterapêutico, começou a ler. O interessante é que Maria tinha como preferência os jogos que requerem leitura.

Foram percebidas dificuldades, mas Maria demonstrou reconhecer letras e palavras. Isso foi se tornando cada vez mais claro no decorrer dos atendimentos; a cada um deles, Maria lia melhor. Deve-se ressaltar que ela copiava qualquer texto de letra de forma com letra cursiva. Isso quer dizer que reconhecia todas as letras do alfabeto.

Maria passou a levar alguns livros para ler durante a sessão, livros que já tinha lido outras vezes. Ela os conhecia tão bem que já sabia de cor algumas passagens. Precisava levar exatamente esses para evitar o que, para ela, seria um constrangimento, o erro. Com o tempo, passou a ler outros desconhecidos por ela. Cada vez mais, desafiava os próprios limites.

Durante os quatro primeiros meses de psicoterapia, Maria demonstrou algumas dificuldades em lidar com seus sentimentos. O mais marcante deles foi a necessidade de ser aprovada pelas pessoas. É como se ela precisasse ser boa o bastante para receber 
o amor dos outros. Maria tinha medo de errar e desapontar as pessoas ao seu redor, principalmente aquelas que ela gostaria que a adotassem.

Em alguns momentos, Maria demonstrou se sentir rejeitada, desanimada e desesperançosa. Fugia das lembranças que sua casa de origem evocava. Instantes depois, demonstrava vivacidade, desejava crescer, ter uma família, desfilar fora do Brasil. A ambivalência de sentimentos fez com que Maria alternasse posições de suficiência e de insuficiência. Por vezes, a possibilidade de uma adoção era idealizada como a solução de todo o mal. Por outras, era rejeitada como um lugar obscuro e silenciador de desejos.

Apesar de expor, frequentemente, seu apego em relação aos padrinhos que a visitavam na instituição em que vivia, colocando-os na posição de pais em potencial, Maria desconfiava das relações. Isso ficou explícito quando ela se perguntava sobre os dias em que os padrinhos não a visitavam. Maria não queria apenas ser escolhida por alguém, ela queria escolher.

O abrigo, algumas vezes, era visto como um congelamento ${ }^{3}$, um lugar onde a felicidade era quase uma missão impossível. Nessa perspectiva, Maria se esforçava em capturar o olhar dos padrinhos para que a levassem desse lugar, que lhe parecia frio. Por outro lado, ela encontrava, nesse mesmo lugar, alguns pontos positivos importantes para ela: os cuidadores, os momentos, os amigos, condições que a aqueciam. O seu campo de vivências era ambíguo, sem determinantes para fracassos nem vitórias.

Depois de quatro meses de psicoterapia, Maria se ausentou dos atendimentos por cerca de um mês, durante o período de férias escolares. A madrinha Rita ligou para combinar o dia do retorno. Nesse dia, Rita se esqueceu do atendimento e informou que, se the fosse cobrado o dia em que faltou, sendo esse o combinado durante o contrato, iria tirá-la da psicoterapia. Ela contou que interrompeu o acompanhamento psicopedagógico de Maria justamente por esse motivo, pelo fato de a psicopedagoga ter cobrado uma sessão a que Maria não compareceu. Rita explicou que Maria não estava se arrumando a tempo para a sessão, pois, quando o motorista ia buscá-la, nunca estava pronta. Comentou que ela não fazia os deveres que a psicopedagoga passava e julgava que ela não estava levando a sério o tratamento, e que, por isso, se cansara da sua forma de se comportar. Os atendimentos psicoterapêuticos de Maria continuaram, mas, nessa época, a madrinha já sinalizava o rompimento da relação com Maria.

No retorno das férias escolares, Maria contou que havia passado o Natal na casa de uma tia que visita a instituição e que a tia Rita e o tio Jorge não estavam mais indo visitá-la, porque deviam estar trabalhando muito. Revelou também que estava com saudades de sua outra madrinha, Lúcia. Maria contou que queria ser adotada por ela. Explicou que Lúcia não a havia adotado ainda porque morava com a mãe e as irmãs, e que na sua casa não havia lugar para Maria. Nesse momento, ela se lembrou de um dia em que havia dormido na casa de Lúcia e em que a madrinha havia dormido no chão para que ela dormisse em sua cama. Maria contou que Lúcia havia lhe dito que, quando se casasse iria adotá-la, recordou que, antes, ela também ia sempre ao abrigo, mas que há muito tempo não ia mais, e que, por isso, estava com tantas saudades dela. Antes, elas frequentavam a mesma igreja, e Maria ressaltou que, agora, nem à igreja ela vai mais. Durante três meses, desde que Maria voltou das férias, o tema predominante nos atendimentos foi a saudade da madrinha Lúcia e a falta da tia Rita e do tio Jorge. Maria relembrou passeios com os padrinhos, na pizzaria, no Praia Clube, no Center Shopping. 
A cada sessão, uma demonstração de angústia. Maria persistia em falar dos padrinhos que não a visitavam mais. Insistia em dizer que não queria ser adotada por mais ninguém e que não queria ir para outro país, ao se referir à possibilidade de uma adoção internacional, queria ser adotada apenas pela tia Lúcia. $\mathrm{O}$ sonho de ser adotada pela tia Rita e pelo tio Jorge foi se esmaecendo com o tempo. Sua atenção se voltou para a tia Lúcia, de quem ela assegurou que não iria desistir. Maria ficara sabendo que ela ia se casar e aguardou esperançosa um contato seu; fez um desenho para a tia Lúcia e outro para a psicoterapeuta, quem sabe assim ela pudesse se sensibilizar com o seu sofrimento e levá-la para casa ou levá-la até a madrinha Lúcia.

\section{Resultados}

Analisar as entrevistas com madrinhas de crianças institucionalizadas e o caso clínico de uma criança apadrinhada propiciou a emergência de muitas questões. Uma análise das escutas registradas traz-nos um rico material a ser investigado.

A relação entre madrinhas e crianças acolhidas aponta a delegação de lugares importantes. Inicialmente, a relação é idealizada por ambas as partes (Freud, 1914/1996), um encontra no outro acolhimento afetivo, uma disponibilidade que sugere um lugar de destaque, de exaltação do outro, como se este viesse para aplacar dores e sofrimentos. Logo, a sedução mútua vai se desvelando como uma forma de permanecer nesse lugar ideal (Chasseguet-Smirgel, 1992). A madrinha seduz a criança para que ela (criança) a ame, a exalte, a valorize perante a sua benignidade, enquanto a criança se faz seduzir para que a madrinha a leve para sua casa, traga-Ihe algum alento e esperança de um dia ter um lar como aquele. Mas, como todo processo pode ter um fim, quando as visitas às casas dos padrinhos se tornam mais constantes, a convivência entre eles rompe a ilusão (Winnicott, 1975) criada no início do relacionamento, fazendo-se presentes as feridas da alma, que fazem irromper as histórias de sofrimento e de abandono das crianças.

Desde o princípio da vinculação, as crianças foram tomadas em uma condição de falta, já marcadas pelo nome de abandonadas, condição que limita o seu amadurecimento emocional. Os padrinhos se colocaram na posição de salvadores, a daqueles que vieram para aplacar as dores das crianças.

Ambos, inicialmente tomados pelo anseio de serem objetos de desejo do outro, agora se percebem desiludidos. A criança precisa se embelezar para permanecer em uma relação ideal, não pode ser o que é, demonstrar suas angústias, medos, sujeiras e insuficiências. Precisa se mostrar devota à madrinha para que ela não deixe de enxergá-la. O olhar constitutivo dos padrinhos é possivelmente um componente essencial à subjetivação das crianças acolhidas, que se sentem desejadas, queridas, de onde advém a esperança de que os padrinhos queiram adotá-las. Alguns deles usam dessa condição para investigar uma possibilidade de adoção.

Mas o movimento de ir e vir da criança, da instituição à casa dos padrinhos e vice-versa, entre o ideal e a desilusão, sinaliza uma falta de lugar ou um lugar de miserabilidade afetiva, em que a relação com o outro só faz aumentar a falta. O lugar não é a casa de origem, não é a instituição de acolhimento, nem a casa dos padrinhos. O encontro desse lugar fica cada vez mais distante no imaginário da criança acolhida, posto que intensamente idealizado.

A relação é marcada pela parcialidade, os padrinhos buscam as crianças quando podem. Não há propriamente um comprometimento, um laço afetivo simbólico que sustente a 
relação, por isso, tudo pode deixar de existir a qualquer momento. As crianças são, por vezes, tratadas como mercadorias, usadas para satisfazerem momentaneamente $\mathrm{o}$ desejo de alguns padrinhos, para, de modo subsequente, entrarem em desuso.

A falta de uma sustentação simbólica na relação entre a criança e a madrinha faz com que esta saia da condição de sujeito para a posição de vítima, digna de dó, perante o julgamento piedoso do outro. Os discursos sobre bondade e amor ao próximo (Kehl, 2002) encobrem sentimentos de onipotência, de engrandecimento do eu à custa do outro (Birman, 2006), apontado como abandonado.

O que move o desejo de apadrinhar crianças em situação de acolhimento institucional são as lacunas subjetivas, a solidão, a carência afetiva, as perdas de entes queridos, os divórcios e as situações diárias que colocam as pessoas em contato com um sofrimento que desejam suturar, lacunas que são depositadas no outro-criança acolhida, que se traduz por uma relação não simbolizada, marcada pelo desalento (Birman, 2006), no qual não há espaço para o outro.

Uma análise sucinta da história infantil de Cinderela permitirá uma discussão mais crítica e apurada da função de madrinha e de sua vinculação à criança acolhida.

\section{Discussão}

\section{Mãe, madrasta e madrinha: as três faces maternas em uma história sem fim}

A história infantil Cinderela atravessou os limites do tempo. Apesar de termos hoje várias versões, sua essência permanece (Corso \& Corso, 2006). Trata-se de uma bela e bondosa jovem, que cedo perdera a mãe e que, por sua vez, tivera seu lugar ocupado por uma mulher com quem seu pai se casara. A madrasta tem duas filhas, que também vêm morar em sua casa. Cinderela é mantida pela madrasta como serviçal e, perante essa realidade, vê-se impossibilitada de ir ao baile promovido pelo príncipe do reino. Maltrapilha, Cinderela é visitada por uma fada madrinha que a prepara para que ela possa ir ao baile. Assim, seu desejo se concretiza. Ela vai ao baile e desperta o interesse do príncipe, que só tem olhos para ela. Mas, como o encanto tinha hora para se desfazer, e Cinderela tem que deixar o palácio imediatamente; nesse momento, perde seu sapatinho de cristal, que é achado pelo príncipe que, a partir de então, tenta encontrar o seu par. A moça em quem coubesse o sapatinho seria a escolhida para ocupar o lugar de princesa. Novamente em trajes sujos e velhos, Cinderela não se parece como uma possível candidata ao posto. Mas o sapatinho vem ao seu encontro, e eles vivem felizes para sempre.

Pela síntese da história de Cinderela, podemos perceber a presença de figuras significativas na vida da bela jovem: sua mãe, madrinha e madrasta. A mãe, tida como bondosa, admirável e frágil, a madrasta má, representante da disputa pelo amor do pai, e a fada madrinha, a lembrança boa de uma infância em que a mãe a completava em um laço de amor (Corso \& Corso, 2006).

As figuras significativas que destacamos são, na verdade, três faces maternas, ou seja, a mãe ou substituta carrega consigo o lugar de mãe, madrasta e madrinha ao mesmo tempo (Corso \& Corso, 2006). A mãe de Cinderela, que, na maioria das versões, morre antes mesmo de a história começar, é a mãe que perdemos quando nos separamos dela, no tempo chamado, por Winnicott (1975), de desilusão. Nesse momento, o bebê transita entre um estado de fusão com a mãe para outro, em que se relaciona com ela como algo externo e separado dele. No estado de 
ilusão, a mãe é aquela que completa os filhos, uma vez que eles acreditam estar de posse dela. Essa mãe é perdida, tanto na história de Cinderela como na de cada um de nós como sujeitos de desejo, e, por isso, morre, o que não significa que ela tenha se perdido em nosso imaginário. É através da figura da madrinha que essa imagem de boa mãe poderá ser restituída. Corso \& Corso (2006) se referem à madrinha como "o que decantou do antigo amor dos pais, agora morto, desencarnado (...)" (p. 111). A madrasta vem para coroar uma relação mãe-filha em que o pai aparece superposto à importância do bebê (Corso \& Corso, 2006).

O olhar do príncipe para Cinderela nos remete ao olhar da mãe para seu bebê em estado de ilusão, e o dom da fada madrinha é o de "restituir algo que uma filha já teve, quando era objeto do olhar materno apaixonado de que os pequenos se nutrem" (Corso \& Corso, 2006, p.111). Quando a madrinha surge, encontramos a possibilidade de uma reconciliação com a dimensão boa da mãe, identificando-se com os seus bons atributos. É essa figura que preserva o lado bom da mãe da primeira infância. Por ter desejado demasiadamente o seu bebê, essa mãe idealizada ficaria isenta de sentimentos hostis (Corso \& Corso, 2006), daí a importância da função de madrasta, a quem a criança pode dirigir toda a sua agressividade, e que, na verdade, é a mesma mãe, só que tomada por um lugar que frustra e não apenas sacia. É fundamental pensarmos que a mãe que sustenta é a mesma mãe que pune e a mesma que encanta. São as respectivas faces maternas de mãe, madrasta e madrinha.

A história de Cinderela, ao enfatizar a criança órfã de mãe e pouco amada pelo pai, remete-nos ao lugar que ocupam as crianças institucionalizadas, que se encontram na posição de preteridas por suas famílias de origem. A empatia pela história é despertada pelas características ressaltadas na figura de Cinderela, assim como no caso das crianças institucionalizadas, o que nos aproxima da rivalidade entre pais e filhos, em que estes, por vezes, se sentem injustiçados, exigidos, assim como pouco amados pelos pais (Corso \& Corso, 2006). Além disso, a exposição dessa rivalidade desmistifica a intensa idealização do amor materno, mostrando suas ambiguidades (Corso \& Corso, 2006).

As faces maternas encarnadas na figura de mãe, madrasta e madrinha também nos levam a um lugar onde a função do apadrinhamento deixa suas marcas. As madrinhas a quem tanto nos referimos neste estudo se compõem desses vários elementos maternos, primeiramente, como mulheres que buscam, na condição de amadrinhamento, um amparo para a dor, as perdas e a solidão, como que tomadas pela condição de filhas. Cada uma com suas vivências particulares, as madrinhas se apossam desse lugar de fragilidade, de dependência e de necessidade de amparo, e encontram na figura das crianças um porto seguro, com todas as suas disposições iniciais de oferecer amor e carinho àquelas que tanto precisam delas. No lugar de filhas, as madrinhas sofrem de um desamparo, também sentido pelas crianças da instituição, afastadas do amor primeiro, nutrido pela mãe perfeita e boa, muitas vezes presente apenas no imaginário, mas perdida na infância.

Encarnadas na posição de madrinhas de crianças institucionalizadas deparamo-nos com uma figura maternal, bondosa, que se encanta e encanta a criança abrigada, como a fada madrinha de Cinderela. A madrinha eleva a criança a um lugar de importância, de majestade, despertando nela a ilusão da onipotência perdida nos primórdios, e viceversa. Apresenta-se, pois, uma relação dual que nos impulsiona à atitude de devoção materna no início da vida psíquica. Assim, a madrinha também se sente completa e majestosa, como na primeiríssima relação 
mãe-bebê. Mas o corte feito pela figura paterna irá barrar esse envolvimento ideal (Jerusalinsky, 2005), levando o olhar da madrinha para outras direções. Só assim a criança irá amadurecer, pois, se permanecer nesse vínculo simbiótico, estará fadada a se perder. A relação entre a criança e a madrinha pode se findar em um acorrentamento de fundo perverso, em que uma seduz a outra para permanecer nesse lugar idealizado.

É importante destacar que a função paterna não precisa ser necessariamente a de um pai que interrompa esse estado de ilusão, mas a da própria madrinha a se desviar para outros lugares que apontarão a realidade, desmistificando a santidade exaltada nos discursos sobre o amor materno. Nesse momento, a criança pode se sentir frustrada, abandonada, mas desejosa de reencontrar o paraíso perdido.

Quando o estágio de idealização se rompe, temos algo como a madrasta, figura que enxerga a criança como ela realmente é, e não em uma condição idealizada, assim como a criança abrigada por vezes percebe a madrinha como uma madrasta. Esta é aquela face da madrinha que frustra, quando não busca a criança para passear todo fim de semana, aquela que pune, quando a criança faz algo que foge às suas expectativas. É a mesma mãe nossa de cada dia, mas sob as vestes de maldade, descaso e desatenção ante a figura frágil da criança. A madrasta representa, também, a maldade da vida que se avizinha pela instituição fria, que visa aos seus interesses como mantenedora de condições físicas e materiais para as crianças. Há ainda a desconfiança na genética que atormenta o pensamento das madrinhas quando fantasiam sobre a possível adoção de suas afilhadas. Estas, na face de madrastas, denunciam as imperfeições das crianças e se atemorizam com a possibilidade de que elas carreguem, em sua carga genética, psicopatologias graves ou mesmo que elas queiram procurar os pais biológicos no futuro, devido à ideia da preponderância do laço sanguíneo perante o laço afetivo (Vargas, 1998).

Ao mesmo tempo em que frustra, a madrinha encarna novamente a função de fada madrinha, que, por seu afeto, faz a criança reviver a ilusão da completude uma vez experimentada, preservando os aspectos bons da mãe perdida, que jamais reencarnará, mas que não nos deixará esquecer que há algum alento, confiança e repouso nessa relação.

Podemos perceber que a figura de destaque neste estudo é a madrinha. O padrinho fica como o pai de Cinderela, pouco falado, pouco realçado, como vemos ainda nos dias de hoje, quando nos perguntamos: Onde está o pai? O pai de Cinderela não aparece para protegê-la em momento algum da história. Apresenta-se apenas como um servo das vontades da madrasta, indiferente ao fato de a filha ser tratada como escrava. Isso nos leva a pensar na função paterna, atualmente, como a função do pai soberano, detentor da palavra e protetor, que aparece nas vestes de padrinhos que tampouco se fazem presentes, que se envolvem muito menos nas relações com as crianças abrigadas que as madrinhas, o que merece outro estudo.

É importante considerarmos que os papéis de mãe, madrasta e madrinha não são fixos, nem precisam estabelecer uma ordem para se dar. Eles vão e vêm, tal como na relação ambígua da criança abrigada com seus padrinhos. O risco que corremos é o de reduzir as madrinhas à condição de madrastas más, e de ignorarmos toda a importância de seu envolvimento com a criança em seu processo de amadurecimento psíquico, mesmo que cercado de limitações no que diz respeito a uma real sustentação de um laço simbólico entre as madrinhas e as crianças. 


\section{Conclusões}

A análise das entrevistas com madrinhas de crianças institucionalizadas possibilitou uma avaliação das relações vinculares constituídas e constituintes do processo de apadrinhamento. Dentre eles, havemos de destacar o lugar da criança como depositária de aspectos conflitivos dos padrinhos, que projetam nas crianças aspectos dos quais querem escapar em função da angústia que despertam, aspectos como a necessidade de ser amado e exaltado, mascarados pela condição bondosa, à espera de ser visto e tomado em consideração pelo outro, e a busca pela felicidade, em que o outro é usado como um meio para alcançá-la, na ilusão de que irá preencher tudo aquilo que the falta. Por essas razões, o outro é colocado na posição de abandonado, daquele que não tem, em que é instaurada a falta, enquanto o padrinho aparece como a figura que pode salvar a criança dos infortúnios, desconsiderando o seu próprio desamparo. Na realidade, o padrinho quer ser salvo, quer ser também apadrinhado pela criança. Em contrapartida, a criança se faz depositária de todos esses aspectos, colocando-se em um papel de vítima, que precisará sempre do outro para preencher suas próprias lacunas. Essa relação se faz coroar em um aprisionamento vincular de angústias impensáveis e indizíveis, que se ancoram no tempo, demarcando desatinos, frustrações e dor.

Pudemos refletir sobre questões fundamentais da existência humana, como o narcisismo, o desamparo e seus desdobramentos em forma de masoquismo, perversão, onipotência, manifestações do psiquismo do sujeito em busca de ser amado, cuidado e valorizado pelo outro (Freud, 1914/1996), por vezes, esbarrando nos interditos do superego, valendo-se do que for preciso para fazer o outro submisso ao gozo, despertado em uma relação idealizada, como a das madrinhas e crianças em situação de acolhimento institucional. A grande preocupação que levantamos ao longo deste estudo é a sustentabilidade dessa relação. Trata-se de uma questão que não pode ser simplesmente respondida, mas que precisa ser percorrida por todos aqueles que se interessam pela dinâmica que circunda o campo de acolhimento à infância. Temos um longo caminho pela frente, no que diz respeito a compreensões e mobilizações que favoreçam ao máximo o desenvolvimento infantil além de condutas mais saudáveis nesse contexto.

Analisar as relações que se dão em um campo institucional, atravessadas por linhas interrompidas, leva-nos a visitar lugares de angústia, de desamparo, de acusação, de isenção e de salvação. Somos tomados por manifestações psíquicas de onipotência, pois cada um que se debruça sobre essa realidade da infância abrigada percebe-se responsável por mudar um contexto de tamanha complexidade, entremeado de inúmeras forças de poder. O que esperamos é que sejam apenas visitas, que não criemos moradia nesses lugares, ora confortáveis, ora tão obscuros, que possamos transitar por eles extraindo reflexões que nos sirvam de suporte para compreender, e então atuar no sentido de promover mudanças que beneficiem a lógica institucional vigente. Para isso, havemos de nos descolar dos pré-conceitos aí estabelecidos e legitimados que nos convidam a um posicionamento moral em relação à função do apadrinhamento. Como vimos na discussão sobre as três faces maternas (Corso \& Corso, 2006), as madrinhas não são boas ou más, são figuras que se misturam e se refazem a todo momento, ora sob a face da mãe saudosa, ora da madrinha ideal, ora da madrasta castradora; uma perpassa a outra, caracterizando a ambiguidade marcante nas relações de apadrinhamento, e cada uma tem 
sua função essencial ao desenvolvimento psíquico infantil. O risco é a fixação em uma relação idealizada, acorrentando os personagens dessa trama a uma busca incessante por um gozo que, por jamais poder ser pleno, poderá também nunca chegar ao fim.

Diante de tal complexidade, podemos perceber a importância de estarmos imersos na busca pela compreensão da função do apadrinhamento e de outras formas vinculares no contexto institucional, porquanto a significação dessa realidade pode permitir que as instituições responsáveis não sejam tomadas por uma visão limitadora e confusa acerca dos papéis das pessoas que se interessam por atender às necessidades das crianças acolhidas, clarificando e desmistificando o processo em benefício de todos os que estão nele envolvidos.

Levemos adiante este estudo, para que ele possa amparar todos aqueles que lidam com um fenômeno tão ardiloso como esse, e que ele faça emergir novos desejos, pois são eles a fonte de todo conhecimento.

Karollyne Kerol de Sousa

Mestre em Psicologia da Intersubjetividade pelo Instituto de Psicologia da Universidade Federal de Uberlândia Minas Gerais, MG - Brasil.

E-mail: karollyne_sousa@hotmail.com

\section{João Luiz Leitão Paravidini}

Doutor em Saúde Mental pela Universidade Estadual de Campinas, Professor Associado do Instituto de Psicologia Universidade Federal de Uberlândia, MG - Brasil.

E-mail: paravidini@ufu.br

\section{Endereço para envio de correspondência:}

Rua José Ayube, 289, Bairro Fundinho, Uberlândia - MG - Brasil. CEP: 38400-188 


\section{Referências}

Birman, J. (1993). O objeto teórico da psicanálise e a pesquisa psicanalítica. In Ensaios de teoria psicanalítica (pp.12-24). Rio de Janeiro: Zahar.

Birman, J. (2006). Arquivos do mal-estar e da resistência. Rio de Janeiro: Civilização Brasileira.Brasil. (1990). Estatuto da criança e do adolescente. São Paulo: Cortez.

Bueno, S. (2007). Minidicionário da língua portuguesa. São Paulo: FTD.

Chasseguet-Smirgel, J. (1992). O ideal do ego. Porto Alegre: Artes Médicas.

Corso, D. L., \& Corso, M. (2006). Fadas no divã: psicanálise nas histórias infantis. Porto Alegre: Artmed.

Freud, S. (1974). Recomendações aos médicos que exercem a psicanálise. In Edição Standart das Obras psicológicas completas de Sigmund Freud (Vol. 12, pp. 121-133). Rio de Janeiro: Imago. (Trabalho original publicado em 1912).

Freud, S. (1996). Sobre o narcisismo: uma introdução. In Edição Standart das Obras psicológicas completas de Sigmund Freud (Vol. 14). Rio de Janeiro: Imago. (Trabalho original publicado em 1914).

Freud, S. (1997). O problema econômico do masoquismo. In Edição Standart das Obras completas de Sigmund Freud (Vol. 9, pp.197-212). Rio de Janeiro: Imago. (Trabalho original publicado em 1924)

Guerra, A. M. C. (2001, janeiro/junho). A lógica da clínica e a pesquisa em psicanálise: um estudo de caso. Ágora, 4(1), 85-101.

Jerusalinsky, J. (2005). Quem é o Outro do sujeito na primeira infância? Considerações sobre o lugar da família na clínica com bebês. Recuperado em 13 de maio de 2010 de http:// www.estadosgerais.org/encontro/IV/PT/trabalhos/Julieta Jerusalinsky.pdf Kehl, M.R. (2002). Sobre ética e psicanálise. São Paulo: Companhia das Letras.

Neves, A. S. (2009). Família no singular, histórias no plural: a violência física de pais e mães contra filhos. Uberlândia, MG: EDUFU.

Safra, G. (1993). O uso de material clínico na pesquisa psicanalítica. In M. E. L. Silva (Coord.), Investigação e psicanálise (pp.119-132). Campinas, SP.

Silva, S. (2010, março). Famílias estrangeiras lideram adoções. Correio de Uberlândia, p. A3.

Vargas, M. M. (1998). Adoção tardia: da família sonhada à família possível. São Paulo: Casa do Psicólogo.

Venâncio, R. P. (1999). Famílias abandonadas: assistência à criança de camadas populares no Rio de Janeiro e em Salvador - séculos XVIII e XIX. Campinas, SP: Papirus.

Winnicott, D. W. (1975), O brincar e a realidade. Rio de Janeiro: Imago.

Winnicott, D. W. (2000). Da pediatria à psicanálise. Rio de Janeiro: Imago. 